\title{
$\mathrm{R} C \& \mathrm{C}$
}

REVISTA DE CONTABILIDADE E CONTROLADORIA

\section{ESTRUTURAS DE PROPRIEDADE E CONTROLE E O DESEMPENHO DAS COMPANHIAS ABERTAS NÃO FINANCEIRAS NO BRASIL}

\section{OWNERSHIP AND CONTROL STRUCTURES AND THE PERFORMANCE OF NON- FINANCIAL PUBLIC COMPANIES IN BRAZIL}

Recebido em 08.08.2014 | Aceite final em 15.06.2015 |

Nota: este artigo foi aceito pelo Editor Jorge Eduardo Scarpin e passou por uma avaliação double blind review

A reprodução dos artigos, total ou parcial, pode ser feita desde que citada a fonte.

INAJÁ ALLANE SANTOS GARCIA Mestranda em Ciências Contábeis pelo Programa Multi-institucional e Interregional UnB/UFPB/UFRN| Universidade Federal da Paraíba | Cidade Universitária | Campus I | Centro de Ciências Sociais Aplicadas| João Pessoa | Brasil | CEP 58.051-900 | Fone: (83) 9106 6021| e-mail: inajaallane@hotmail.com |

ORLEANS SILVA MARTINS Doutor em Ciências Contábeis pelo Programa Multi-institucional e Inter-regional UnB/UFPB/UFRN| Professor Adjunto da Universidade Federal da Paraíba |Universidade Federal da Paraíba | Cidade Universitária | Campus I | Centro de Ciências Sociais Aplicadas | Ambiente dos Professores| Sala 67| João Pessoa | Brasil | CEP 58.051-900 | Fone: (83) 9106 6021| e-mail: orleansmartins@yahoo.com.br |

\section{RESUMO}

O presente trabalho investiga as relações das estruturas de propriedade e controle com o desempenho financeiro das empresas não financeiras listadas na BM\&FBOVESPA entre os anos de 2008 e 2012. Para isso, foi realizada uma revisão de literatura acerca das estruturas de propriedade e de controle, assim como de sua relação com o desempenho das empresas, medido pelo Retorno sobre o Ativo (ROA), Retorno sobre o Patrimônio Líquido (ROE), Margem Líquida (ML), Lucro por Ação (LPA) e Endividamento Geral (END). Assim, foram coletados os dados financeiros necessários para as análises a partir do banco de dados do Economatica ${ }^{\circledR}$, os quais foram tabulados e analisados por meio de estatística descritiva e de análise de regressões simples com dados em painel desbalanceado e com efeitos aleatórios. No total, após o tratamento de outliers pela técnica de Winsor, foram analisadas 1.660 observações de 332 empresas. Os resultados mostram que tanto a propriedade como o controle das empresas ainda são concentrados, e que a concentração do controle é mais evidente que a de propriedade. Foi possível, ainda, verificar que o ROA está relacionado negativa e significativamente com a concentração de propriedade e de controle e o ROE está positiva e significativamente relacionado à

Revista de Contabilidade e Controladoria, ISSN 1984-6266

Universidade Federal do Paraná, Curitiba, v. 7, n.2, p. 110 -126, mai./ago. 2015. 
propriedade. O END também está relacionado positivamente à propriedade e ao controle. Com isso, este estudo contribui com um recorte da estrutura de propriedade e controle das empresas no mercado brasileiro de capitais após 2008, ano de mudança nas normas contábeis no Brasil e de crise financeira nos mercados de capitais, além de indicar sua relação com a rentabilidade e o endividamento das firmas investigadas.

Palavras-chave: Ação Ordinária. Ação Preferencial. Concentração Acionária. Desempenho Financeiro.

\begin{abstract}
This paper investigates the relationship between ownership and control structures and the financial performance of non-financial companies listed on the BM\&FBOVESPA between the years 2008 and 2012. For this, a literature review of the ownership and control was held, as well as its relationship with firm performance, measured by Return on Assets, Return on Equity, Net Income, Earnings per Share and Debt. Thus, the financial data for the analyzes were collected from the database Economatica ${ }^{\circledR}$, which were tabulated and analyzed using descriptive statistics and analysis of simple regressions with unbalanced panel data with random effects. In total, after treatment with the technique of outliers Winsor, 1,660 observations were analyzed of 332 companies. The results show that both the ownership and the control of the companies are still concentrated, and that the concentration of control is evident that property. It was also possible to verify that the Return on Assets is negative and significantly related to the concentration of ownership and control and the Return on Equity is positively and significantly related to the property. The Debt is also positively related to ownership and control. Therefore, this study contributes with a cutout of the structure of ownership and control of companies in the Brazilian capital market after 2008, the year of change in accounting standards in Brazil and the financial crisis in the capital markets, and indicate its relation to profitability and the Debt of firms investigated.
\end{abstract}

Keywords: Common Stock. Preferred Stock. Stock Concentration. Financial Performance.

\title{
1 INTRODUÇÃO
}

Entre as principais estratégias de gestão de uma empresa, está a busca por recursos suficientes para financiar suas operações. No ambiente de negócios, uma das principais fontes de recursos é o mercado de capitais, por meio da abertura do capital da companhia, que permite o desenvolvimento das empresas ao mesmo tempo em que contribui para a economia do país, pois fortalece as empresas e lhes permite a possibilidade de gerar novos empregos, contribuindo para o desenvolvimento do país (BORSATO; PIMENTA; LEMES, 2010).

No processo de abertura do capital, as empresas ofertam ações, ou seja, colocam à venda no mercado de valores mobiliários títulos nominativos que dão direitos sobre sua propriedade. Os compradores dessas ações, por sua vez, tornam-se acionistas da empresa e passam a ser detentores 
de sua propriedade e, em alguns casos, do controle de sua gestão. No mercado brasileiro de capitais há dois tipos de ações que as empresas podem ofertar: as ações ordinárias (ON) e as preferenciais (PN). Essas duas classes se distinguem basicamente pelo fato de a primeira conceder, a quem as possui, direito de voto nas Assembleias Gerais realizadas pela empresa, o que não acontece com a segunda classe, que concede aos seus detentores a prioridade no recebimento dos dividendos da empresa. Assim, diz-se que o investidor de ações ON tem direito de voto e sobre o fluxo de caixa, enquanto o investidor de ações PN tem direito apenas sobre o fluxo de caixa da empresa.

No Brasil, Vieira e Mendes (2006) destacam que a evolução histórica do mercado de capitais foi baseada em uma estrutura familiar e em investidores institucionais que se posicionavam normalmente fora do controle da firma. Na visão de Duarte and Young (2009), essa situação desperta atenção em mercados emergentes, como o Brasil, especialmente devido à concentração de um grande volume de ações nas mãos de poucos investidores.

Para Campos (2006), no que se refere ao tipo de acionista, no Brasil eles podem ser assim identificados: governo, famílias, instituições financeiras e entidades não financeiras. Dessa forma, pode ser notada a presença de um mix de investidores nas empresas brasileiras, com possibilidade de concentração acionária em um determinado tipo de investidor, aumentando a probabilidade de que um desses tipos de acionistas seja o majoritário, de forma que comande a maior parte das ações de uma empresa. Assim, a identificação da concentração de acionistas determina a chamada estrutura de propriedade, o que é ratificado por Campos (2006). Nesse aspecto, destaca-se, além da concentração da propriedade, a concentração do controle, isto é, do direito de voto.

Isso é corroborado por La Porta et al. (1998) quando observam que a estrutura de propriedade predominante na maioria dos países, especialmente da América Latina, revela a concentração de propriedade e controle. Destarte, uma vez verificada a concentração de controle, isto é, de ações ordinárias nas mãos de apenas um acionista, diz-se que o controle é majoritário, pois o mesmo detém o controle da entidade. Assim, no que tange à Contabilidade, é relevante verificar se aspectos intrínsecos às firmas, como as estruturas de propriedade e de controle das empresas, têm alguma influência sobre o desempenho das mesmas, uma vez que trata quantitativa e qualitativamente da sua estrutura, como Campos (2006) destaca.

A respeito dos estudos sobre estrutura de propriedade e desempenho, destacam-se Demsetz e Lehn (1985), McConnel e Servaes (1990) e Hermalin e Weisbach (1991), além de Silveira, Barros e Famá (2008) que afirmam que é comum encontrar na literatura internacional resultados que apontam para uma relação positiva e significativa entre essas variáveis e o desempenho das firmas. Quanto à literatura brasileira, é possível observar que o tema é pouco explorado, destacando-se especialmente os estudos de Campos (2006), Okimura, Sliveira e Rocha (2007) e Silveira, Barros e Famá (2008). Com isso, tendo em vista as modificações recentes no que se refere à liquidez e à contabilidade das empresas no Brasil, especialmente a partir do advento da Lei № 11.638/2007, este estudo surge com o objetivo de investigar as relações das estruturas de propriedade e controle com o desempenho financeiro das empresas não financeiras listadas na BM\&FBOVESPA entre os anos de 2008 e 2012.

\section{REVISÃO DE LITERATURA}

\subsection{ESTRUTURAS DE PROPRIEDADE E CONTROLE NO BRASIL}

A estrutura de propriedade das empresas é um tema que tem sido explorado na literatura de finanças, especialmente sob dois aspectos: os graus de concentração e dispersão do capital e a natureza dos proprietários (DELCl; BEUREN, 2012). Nessa literatura, tal estrutura é considerada como o principal mecanismo interno de governança corporativa, principalmente em países com alta 
concentração de propriedade, como é o caso do Brasil (DAMI; ROGERS; RIBEIRO, 2007). Dessa forma, está fortemente ligada ao desempenho da companhia.

Na visão de Coutinho, Amaral e Bertucci (2005), a expressão governança corporativa está associada à definição de um sistema de relações entre os acionistas, auditores independentes e executivos da empresa, liderados pelo Conselho de Administração. Sob esse contexto, a estrutura de propriedade das firmas é vista como um mecanismo de governança, pois revela como se divide a propriedade da empresa e, paralelamente, seu controle. Paralelamente, tem influência na gestão da empresa e, por conseguinte, em seu processo de tomada de decisão.

Segundo Gorga (2008), a estrutura de propriedade e de controle das empresas brasileiras possui uma elevada concentração, alcançada através de pirâmides societárias, acordos entre os acionistas e emissão de ações sem direito a voto. Evidências empíricas comprovam a alta concentração acionária no Brasil (CAMPOS; 2006; SARLO NETO; LOPES; DALMÁCIO, 2010; CAIXE; KRAUTER, 2013), diferentemente de países como os Estados Unidos, onde segundo Berle and Means (1932) se observa a propriedade diluída entre um grande número de pequenos acionistas.

Alguns autores como La Porta et al. (1998), Leal, Silva e Valadares (2002) explicam que essa alta concentração acionária é normal em países onde não há uma proteção legal adequada para os investidores, como em países emergentes, necessitando de uma maior participação dos acionistas nas empresas, para exercerem o monitoramento dos gerentes da entidade. Sendo assim, devido à frágil proteção legal, a concentração de capital passa a ser uma característica marcante.

Sarlo Neto, Loss, Teixeira e Lopes (2005) ratificam essa observação ao analisarem as características do mercado acionário brasileiro, considerado emergente, oportunidade na qual esses autores afirmam que neste mercado há características próprias e diferentes daquelas observadas em mercados desenvolvidos, como o mercado dos Estados Unidos. Entre elas, destacaram: pouca proteção aos acionistas minoritários; forte concentração de controle acionário; e excesso de regulamentação, apesar de sua baixa proteção aos acionistas.

Isso desperta atenção, pois como ressaltam Hahn, Nossa, Teixeira e Nossa (2010), características como a fraca proteção legal e a forma como as empresas brasileiras se relacionam com os acionistas minoritários enfraquecem o mercado brasileiro de capitais, levando-a a perder credibilidade diante de mercados estrangeiros. Por isso surge a necessidade de instrumentos que fortaleçam a proteção aos investidores, como as práticas diferenciadas de Governança Corporativa. Entre aquelas incentivadas no mercado brasileiro, com vistas a fortalecê-lo, destacam-se a exclusiva emissão de ações ordinárias e o estímulo à pulverização do capital das firmas.

Esta classe de ações, ordinárias, concede ao seu portador o direito de voto e influência nas decisões da empresa, como: aprovar as demonstrações contábeis, decidir sobre a destinação dos resultados, além de participar das eleições da diretoria e intervir na mudança do estatuto. Por esses motivos, é natural se esperar que empresas com tal estrutura de propriedade possuam melhor governança e apresentem melhores resultados do que empresas que possuem ações do tipo preferencial, que não concede direito de voto nas Assembleias Gerais da companhia.

Por outro lado, Gonzaga e Costa (2009) destacam que em firmas com forte concentração acionária, como acontece no Brasil, o acionista controlador tem o poder de decidir sobre a destinação dos resultados, podendo se favorecer com algumas medidas. Isto é, se o lucro líquido é a base para o cálculo dos dividendos, pode ser que o acionista controlador tenha interesse em realizar escolhas contábeis com base no entendimento de que ele pode ter interesses diferentes dos demais investidores. 
Na literatura corrente, é possível verificar que, na média, as estruturas de propriedade e de controle das empresas no Brasil têm se modificado. A Tabela 1 mostra o total de ações, ordinárias e preferenciais para a propriedade e apenas ordinárias para o controle, considerando o maior acionista, controlador, ao longo dos últimos anos, evidenciando a alta concentração das ações no mercado brasileiro.

É possível verificar que a concentração de propriedade e controle é alta, porém, pode-se perceber que os valores encontrados por Campos (2006) estão acima daqueles encontrados por Caixe e Krauter (2013), em estudo recente, o que pode indicar uma redução dessa concentração. Todavia, deve-se considerar as amostras diferentes analisadas pelos pesquisadores. Assim, isso pode estar relacionado apenas à quantidade de empresas que fizeram parte da amostra No mais é possível identificar a alta concentração nas mãos de um único acionista.

Tabela 1- Concentração de propriedade e controle do maior acionista durante os anos (\%)

\begin{tabular}{cccc}
\hline Média por Autor & Ano & Propriedade & Controle \\
\hline \multirow{3}{*}{ Campos (2006) } & 1998 & - & 58,99 \\
& 1999 & - & 61,11 \\
& 2000 & - & 61,36 \\
\hline & 2001 & 39,81 & 57,14 \\
& 2002 & 38,51 & 57,09 \\
& 2003 & 42,53 & 60,55 \\
Caixe e Krauter (2013) & 2004 & 47,32 & 65,96 \\
& 2005 & 43,41 & 61,21 \\
& 2006 & 41,69 & 57,53 \\
& 2007 & 41,36 & 57,52 \\
& 2008 & 41,65 & 53,96 \\
& 2009 & 40,23 & 50,05 \\
\hline
\end{tabular}

\subsection{DESEMPENHO FINANCEIRO DAS EMPRESAS}

O desempenho financeiro de uma empresa é fruto das informações geradas a partir da divulgação de suas demonstrações contábeis, por meio da análise de indicadores financeiros (CAPOBIANGO et al. 2012). Segundo Carneiro e Silva (2010), esses indicadores são denominados de contábeis-financeiros, acrescentando que eles são responsáveis por informar sobre o grau de retorno atingido pelos investimentos, além de fornecer outros subsídios ao processo decisório.

Levando-se em conta que os indicadores financeiros são extraídos das informações contábeis apresentadas nos demonstrativos, é necessário despertar para o novo cenário das empresas situadas nos países que adotaram as Normas Internacionais de Contabilidade, conhecida em todo mundo como International Financial Reporting Standards (IFRS). No Brasil, essas normas já possuem efeitos a partir de 2008, com a promulgação da Lei № 11.338/2007, e de acordo com Ivo (2012) trouxe modificações no reconhecimento, mensuração e divulgação dos elementos patrimoniais e de desempenho. Este autor complementa e afirma que dessa forma, esperam-se implicações nos diferentes padrões de indicadores econômicos, financeiros e de desempenho oriundos das novas demonstrações contábeis.

Além das informações contábeis, outros elementos e características, como a estrutura de propriedade e controle, podem influenciar o desempenho das empresas que são medidos através dos indicadores financeiros (OKIMURA, 2003). O estudo realizado por Campos (2006) incrementa que 
a identidade dos acionistas também é uma característica que influencia o desempenho organizacional.

Diante desse cenário, pode-se observar a presença frequente de alguns índices utilizados para medir o desempenho das empresas, como o Retorno Sobre o Ativo (ROA), o Retorno Sobre o Patrimônio Líquido (ROE), a Margem Líquida (ML), o Lucro por Ação (LPA) e o índice de Endividamento (END). Neste estudo, esses índices são utilizados para medir o desempenho e investigar a existência ou não de relação entre eles e a estrutura de propriedade e controle.

Nesse sentido, Bastos, Nakamura, David e Rotta (2009) afirmam que o ROA é a medida de desempenho mais utilizada pelas empresas que atuam no Brasil, seguida do EVA ${ }^{\oplus}$, ROE e LPA. Biral (2010) destaca a importância do ROA na análise de performance da empresa, uma vez que relaciona a geração de receitas sobre os ativos totais. Esse mesmo autor ainda enfatiza que o ROE, é um importante indicador de desempenho, principalmente do retorno sobre o capital.

De acordo com Peterson e Peterson (1996), os indicadores ROA, ROE e LPA possuem vantagens por estarem disponíveis nos relatórios financeiros das empresas e por serem fácil de se calcular e compreender. Isso talvez justifique a grande utilização desses índices nas pesquisas. Com relação ao LPA, ou lucro por ação, Bastos et al. (2009) observam que é uma medida de lucro tradicional e também uma das métricas mais focadas por executivos e analistas de mercado por revelar o quanto de lucro cada ação está gerando.

A Margem Líquida (ML) foi escolhida como indicador de desempenho, porque, de acordo com Campos (2006), representa melhor a relação entre os lucros líquidos e as vendas. E o END, foi selecionado para representar o endividamento total da empresa, isto é, representa quanto de capital de terceiros foi utilizado para financiar os investimentos da empresa, o que está diretamente ligado aos investidores, componentes da estrutura de propriedade e de controle.

\subsection{ESTRUTURAS DE PROPRIEDADE E CONTROLE E O DESEMPENHO DAS EMPRESAS}

O Comitê de Pronunciamentos Contábeis (CPC, 2010) destaca que o objetivo das demonstrações contábeis é fornecer informações sobre a posição patrimonial e financeira, o desempenho e as mudanças na posição financeira da entidade, que sejam úteis a um grande número de usuários em suas avaliações e tomadas de decisão econômica. Sendo assim, essas demonstrações são base para o cálculo dos índices de desempenho da companhia.

No mercado de capitais, ao se referir à Contabilidade, pode-se dizer que ela é responsável por divulgar informações através das demonstrações financeiras, para que os investidores analisem as empresas e decidam se vale à pena fazer o investimento ou não, ou, ainda, avaliar o quando essas empresas estão sendo bem geridas. Diante disso, é possível perceber que os demonstrativos preparados pela contabilidade possuem relevância na avaliação desses investimentos.

Sarlo Neto, Lopes e Dalmácio (2010) corroboram que na literatura internacional é possível observar um conjunto de evidências que indica a importância dos números contábeis divulgados para o mercado acionário. Nesse contexto, Campos (2006) destaca a relação entre os custos e benefícios da concentração da propriedade, afirmando que maior concentração implica melhor desempenho porque reduz os custos de propriedade. Desta forma, presume-se que a estrutura de propriedade e controle das empresas possua relação direta com seu desempenho.

Aldrighi e Oliveira (2007) mostraram que, nas companhias brasileiras de capital aberto, investigadas no período entre 1997 e 2002, a concentração de propriedade, aliada à presença de estruturas 
piramidais, afetaram negativamente o desempenho das empresas, na figura do lucro operacional sobre os ativos. Porém, Okimura, Silveira e Rocha (2007), com uma amostra de 1998 a 2002, constataram que há uma relação linear positiva entre o lucro operacional sobre o ativo total e as variáveis de estrutura de propriedade e de concentração de votos. Apesar da relação positiva observada, não foi possível verificar as razões, visto que os resultados foram difusos.

Dessa forma, com base na literatura existente e nas evidências apresentadas, pode-se esperar que as estruturas de propriedade e de controle concentradas tenham influência sobre o desempenho das empresas, uma vez que estão relacionadas a aspectos intrínsecos a entidade.

\subsection{DESENVOLVIMENTO DAS HIPÓTESES DA PESQUISA}

O mercado acionário brasileiro tem uma característica própria de possuir mais de um tipo de ação, os quais concedem aos seus detentores diferentes direitos, sejam de voto nas decisões em assembleia ou sobre os fluxos de caixa da forma (CAMPOS, 2006). Ainda, evidências apontam que a estrutura de propriedade no Brasil é alta e concentrada nas mão de poucos acionistas (CAMPOS, 2006; SARLO NETO; LOPES; DALMÁCIO, 2010). Com base nisso, surge a primeira hipótese de pesquisa deste estudo:

Hipótese 1: Empresas abertas não financeiras no Brasil possuem elevada concentração de propriedade.

Ainda no que se refere à essa característica do mercado brasileiro, Martins e Paulo (2014) destacam que é característico desse mercado a existência de um alto volume de emissão de ações preferenciais, sendo este tipo de ação o mais negociado em algumas companhias. Ao decidir investir em ações, o investidor opta pelo tipo de ação que the confere a prioridade desejada, seja exclusivamente de remuneração, por meio de ações $\mathrm{PN}$, ou de controle da firma, por meio de ações com direito a voto (ON). Neste mercado, porém, há um histórico de maior concentração de ações ordinárias, sendo as preferenciais mais dispersas (CAMPOS, 2006; CAIXE; KRAUTER, 2013). Assim, surge a segunda hipótese:

Hipótese 2: Empresas abertas não financeiras no Brasil possuem maior concentração de controle do que de propriedade.

Devido à possibilidade de formar uma estrutura piramidal de controle, controladores tendem a concentrar maior quantidade de ações ordinárias do que preferenciais (SARLO NETO; LOPES; DALMÁCIO, 2010). Aliado a isso, Campos (2006) e Silveira, Barros e Famá (2008) observam que a concentração da propriedade e controle no Brasil implica melhor desempenho porque reduz os custos de agência. Com base nisso, conjetura-se última hipótese de pesquisa deste estudo:

Hipótese 3: Empresas que possuem maior concentração de propriedade e controle possuem melhor desempenho financeiro.

Acrescenta-se que a maior parte das evidências citadas se reportam a dados anteriores ao ano de 2008, em que ocorreu a crise financeira dos Subprime e o início da vigência da Lei № 11.638/2007. Portanto, essas hipóteses são verificadas ao longo do estudo e a rejeição ou não de cada uma delas é indicada com base nos dados, limitando-se à amostra analisada.

\section{METODOLOGIA}

Revista de Contabilidade e Controladoria, ISSN 1984-6266

Universidade Federal do Paraná, Curitiba, v. 7, n.2, p. 110 -126, mai./ago. 2015. 


\subsection{POPULAÇÃO E AMOSTRA}

A população deste estudo foi composta por todas as empresas não financeiras listadas na BM\&FBOVESPA durante os anos de 2008 a 2012. As empresas financeiras foram excluídas por apresentarem regulação específica e estrutura patrimonial diferenciada, além de operarem sempre de forma alavancada, ou seja, com um grau de endividamento alto, o que poderia distorcer os resultados, Dessa forma, sua amostra foi definida após a exclusão das empresas que não apresentaram as informações necessárias à realização do estudo.

A coleta dos dados foi realizada em junho de 2013, quando 353 empresas negociavam 576 ações ativas na BM\&FBOVESPA. Com base nisso, após a coleta das informações de todas as empresas que negociaram suas ações entre 2008 e 2012 (inclusive daquelas que já não estavam na bolsa), a amostra final contou com 332 empresas, perfazendo um total de 1.660 observações ao longo desses 5 anos, em um conjunto de dados em um painel desbalanceado.

\subsection{COLETA DE DADOS}

Para a coleta das informações sobre as estruturas de propriedade e controle direto, assim como dos indicadores de desempenho das firmas, utilizou-se o banco de dados da Economatica . Após a coleta, foi realizada a tabulação dos mesmos para que fossem estimadas regressões lineares simples para se analisar as relações existentes entre as estruturas de propriedade e controle e o desempenho das firmas.

Quanto ao cálculo das medidas de desempenho, o ROA, que mede o quanto de lucro foi gerado pelo ativo da empresa. Esse retorno foi calculado pela Equação 1.

$$
\mathbf{R O A}=\frac{\text { Lucro Líquido }}{\text { AtivoTotal }}
$$

Como medida de desempenho, também se utilizou o ROE, a exemplo de Campos (2006), Dami, Rogers e Ribeiro (2007) e Caixe e Krauter (2013). Esse índice é conhecido no Brasil como Taxa de Retorno sobre o Patrimônio Líquido (TRPL) e representa o retorno que os investidores obtêm por cada real investido. Ele foi calculado a partir da Equação 2.

$$
\text { ROE } / \text { TRPL }=\frac{\text { Lucro Líquido }}{\text { Patrimônio Líquido }}
$$

A Margem Líquida (ML) utilizada por Campos (2006), mostra qual foi o retorno obtido sobre as vendas, isto é, o que sobrou de lucro para a empresa após deduzir todas as despesas. Esse indicador foi encontrado a partir da Equação 3.

$$
\mathbf{M L}=\frac{\text { Lucro Líquido }}{\text { Vendas }} \times 100
$$

O Lucro por Ação (LPA) representa o quanto de lucro líquido cabe a cada ação emitida. Esse índice foi calculado por meio da Equação 4. 


$$
\mathbf{L P A}=\frac{\text { Lucro Líquido }}{\text { Número de Ações Emitidas }}
$$

O índice de Endividamento Geral (END), também denominado de dependência financeira, utilizado no estudo de Kühl, Cherobim e Santos (2008), é o passivo exigível sobre o ativo total e representa o quanto do ativo é financiado por capital de terceiros. Esse indicador foi calculado por meio da Equação 5.

$$
\text { END }=\frac{\text { Passivo Exigível }}{\text { Ativo Total }}
$$

\subsection{REGRESSÕES SIMPLES ESTIMADAS}

Para identificar a relação entre as estruturas de propriedade e controle com o desempenho das empresas, foram utilizados modelos de regressões simples. Tendo em vista a estimação consistente dos parâmetros, foi analisado o modelo de regressão com dados em painel, que melhor se adequou à consistência e eficiência dos estimadores. Assim, foi testada a adequação do modelo pelo Multiplicador de Lagrange de Breusch-Pagan para decidir entre estimação por Pooled Ordinary Least Squares (POLS) ou por efeitos aleatórios, cuja hipótese nula de adequação dos modelos POLS foi rejeitada. Em seguida, foi realizado o teste de Hausman para decidir entre estimação por efeitos fixos ou aleatórios, quando sua hipótese nula de consistência dos estimadores por efeitos aleatórios não foi rejeitada. Por isso foram utilizados modelos com efeitos aleatórios.

Os dados das 332 empresas em um painel desbalanceado. Assim, as regressões simples foram estimadas isoladamente a partir da Equação 6.

$$
\text { Estrutura }_{i t}=\gamma_{0}+\gamma_{1} \text { Desempenho }_{i t}+u_{t}
$$

Onde a variável Estrutura $_{i t}$ indica a estrutura de propriedade ou controle da empresa, $\gamma_{0, \ldots, n}$ são os coeficientes da regressão, Desempenho ${ }_{i t}$ é o indicador de desempenho e $u_{t}$ é o erro aleatório. Tais relações foram investigadas de forma independente, relacionando-se a estrutura de propriedade a cada indicador de desempenho e, em seguida, repetindo-se o procedimento para a estrutura de controle, uma a uma.

\section{ANÁLISE DOS RESULTADOS \\ 4.1 CONCENTRAÇÃO DE PROPRIEDADE E DE CONTROLE}

A propriedade nas empresas de capital aberto no Brasil apresenta um histórico de alta concentração ao longo do tempo (Dami, Rogers, \&Ribeiro, 2007). Neste estudo, durante o período analisado, a média de concentração acionária do maior acionista foi cerca de $43,05 \%$ do total das ações (ON e PN), como apresenta a Tabela 2. Ao comparar esse resultado com a pesquisa realizada por Caixe e Krauter (2013), entre 2001 e 2010, com cerca de 41,38\% das ações possuídas pelo maior acionista, verifica-se que a média da concentração de propriedade é maior, o que ainda é considerado relativamente alto, pois o principal acionista detém quase metade do total das ações. Isso é ainda 
mais evidente quando se observa o percentual de ações totais nas mãos dos cinco maiores acionistas (cerca de 67,31\%), média bem acima da apurada por Leal, Silva e Valadares (2002), que analisou as empresas em 1998, quando os autores encontraram aproximadamente $58,00 \%$ das ações concentradas nesses acionistas.

Analisando as médias de concentração por ano para o maior acionista é possível perceber que, de 2008 para 2009 houve um leve declínio, o que pode ser justificado pela crise financeira mundial, que alcançou o Brasil em meados de 2008, refletindo a saída de investidores do mercado de ações, pois os riscos dos investimentos haviam aumentado. No período estudado o declínio mais significante da concentração foi entre 2011 e 2012, o que pode refletir a tendência de diluição da concentração do capital após a crise.

Esse suposto cenário sugere que o mercado acionário brasileiro vem passando por transformações nos últimos anos, com o aumento do número de investidores e a redução da concentração acionária, mesmo que a passos lentos. Isso é perceptível se consideradas as evidências de pesquisas anteriores (CAMPOS; 2006; CAIXE; KRAUTER, 2013), que revelaram médias de concentração ainda maiores. Nesse contexto, a diminuição da instabilidade do mercado acionário no Brasil pode ser um reflexo da entrada de novos investidores e consequente diluição da propriedade das empresas. Sendo assim, apesar dessa redução, a Hipótese 1 desta pesquisa não pode ser rejeitada, pois as empresas no Brasil ainda apresentam alta concentração de propriedade.

Tabela 2 - Distribuição da propriedade do capital das empresas (\%). 2008 - 2012.

\begin{tabular}{lcccccc}
\hline \multicolumn{1}{c}{ Grupos de acionistas } & $\mathbf{2 0 0 8}$ & $\mathbf{2 0 0 9}$ & $\mathbf{2 0 1 0}$ & $\mathbf{2 0 1 1}$ & $\mathbf{2 0 1 2}$ & No período \\
\hline Maior & 43,42 & 43,00 & 43,71 & 43,19 & 42,24 & 43,05 \\
Três Maiores & 62,66 & 62,18 & 62,05 & 61,32 & 61,96 & 61,98 \\
Cinco Maiores & 68,13 & 68,14 & 66,80 & 66,32 & 67,45 & 67,31 \\
\hline
\end{tabular}

Fonte: Dados da pesquisa.

Quanto à estrutura de controle, é possível observar, a partir da Tabela 3, que em todos os anos (de 2008 a 2012), em termos percentuais, o maior acionista possuiu mais de 50,00\% das ações ordinárias, o que the garantiu o poder de controlar a empresa sozinho. Todavia, de acordo com a legislação vigente no Brasil, vale a pena salientar que esse controle poderia ser exercido com apenas $25,00 \%$ mais uma ação, o que não justifica as médias observadas neste estudo.

É possível identificar forte concentração de controle nas mãos do maior acionista, chegando a 56,07\% no ano de 2008. Em estudo realizado por Okimura, Silveira e Rocha (2007), entre 1998 e 2002, o percentual da concentração de controle nas mãos do maior acionista foi de aproximadamente $76,10 \%$, o que sugere que também houve diminuição da concentração de controle ao longo dos anos. No período investigado, a média de ações nas mãos do maior acionista foi de aproximadamente $52,84 \%$.

Tabela 3 - Distribuição do controle do capital das empresas (\%). 2008 - 2012.

\begin{tabular}{llllllc}
\hline Grupos de acionistas & $\mathbf{2 0 0 8}$ & $\mathbf{2 0 0 9}$ & $\mathbf{2 0 1 0}$ & $\mathbf{2 0 1 1}$ & $\mathbf{2 0 1 2}$ & No períodc \\
\hline Maior & 56,07 & 53,23 & 51,81 & 52,48 & 51,34 & 52,84 \\
Três Maiores & 74,96 & 72,20 & 70,04 & 70,76 & 70,98 & 71,67 \\
Cinco Maiores & 79,36 & 77,24 & 74,32 & 75,16 & 75,67 & 76,23 \\
\hline
\end{tabular}

Fonte: Dados da pesquisa. 
Na estrutura de controle, assim como na de propriedade, é perceptível a redução da concentração de 2008 a 2012. Isso também foi observado por Okimura, Silveira e Rocha (2007) em sua pesquisa que se refere ao período de 1998 a 2002 . E, como dito alhures, isso pode ter ocorrido devido ao aumento de investidores, especialmente na última década. Mais uma vez, a exemplo da concentração da propriedade, foi possível verificar que a concentração do controle nas mãos do maior acionista foi o que revelou maior variação, saindo da média de 56,07\% em 2008 para 51,34\% em 2012. Apesar dessa tendência de queda, essa média ainda é alta, como observaram Okimura, Silveira e Rocha (2007).

A Figura 1 mostra o comportamento das variáveis de concentração de propriedade e de controle para o percentual do maior acionista durante o período analisado. Pode-se observar um leve declínio da concentração de propriedade entre os anos de 2008 e 2009, logo após um leve aumento e, em seguida, a partir de meados de 2010, nova tendência de queda. De forma similar à reta que simboliza a concentração de propriedade segue a reta da concentração de controle, sendo que a oscilação é menor.

Figura 1- Concentração de propriedade e controle para o acionista majoritário. 2008 - 2012.

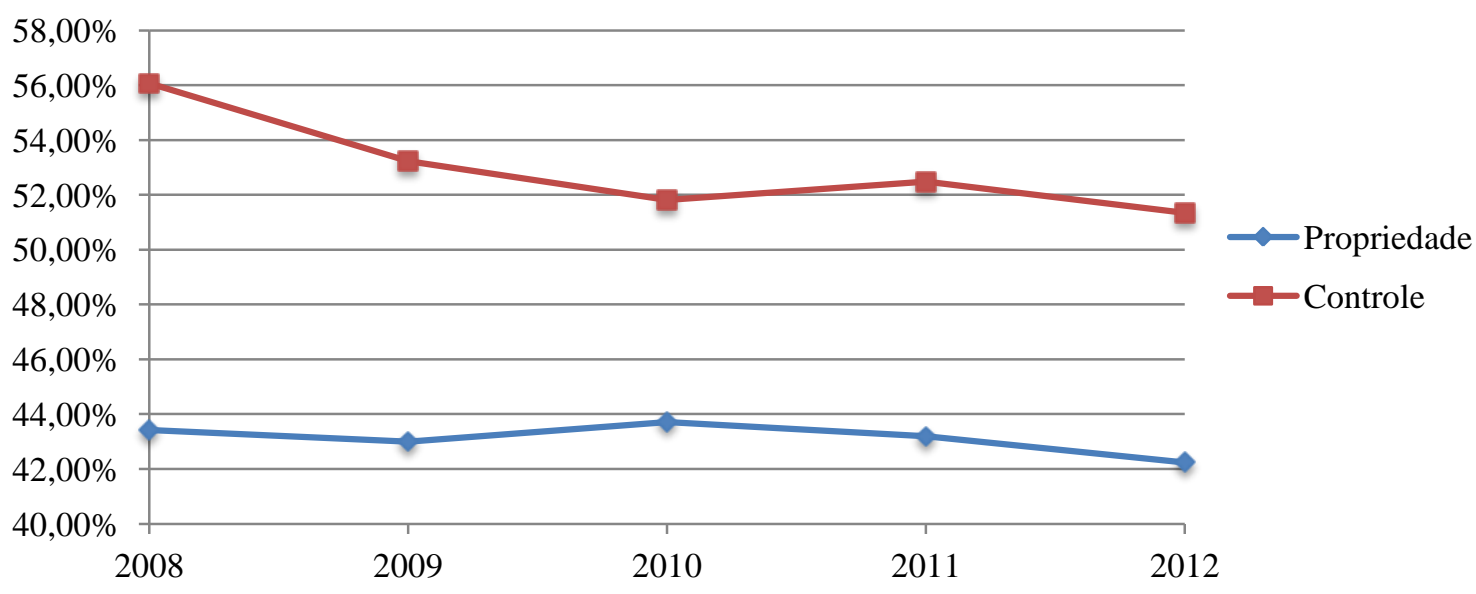

Destaca-se que nos anos de 2008 e 2009 o mercado financeiro mundial passou por uma crise econômica, a qual afetou o mercado brasileiro aumentando as taxas de juros e o risco dos investimentos. Ainda, seus efeitos perduraram por algum tempo, especialmente em 2009 e 2010. Isso pode ter motivado a retirada de capital de alguns mercados, como o brasileiro, o que pode explicar a tendência de alta da concentração no ano de 2010.

Pode-se observar, também, que a concentração do controle é mais perceptível do que a da propriedade, e isso implica dizer que a pulverização das ações das empresas entre os investidores é realizada por meio de ações preferenciais, que não dão direito de voto, como observa Martins e Paulo (2014). Com isso, a Hipótese 2, em que as empresas abertas não financeiras possuem maior concentração de controle do que de propriedade não pode ser rejeitada, cabendo destaque ao grupo do maior acionista, controlador, onde a diferença entre as médias de concentração de propriedade e de controle foi de cerca de 10 pontos percentuais.

Por outro lado, além de calcular as médias de concentração de propriedade e de controle, foram coletadas informações sobre o desempenho financeiro das empresas, medido por meio de indicadores de rentabilidade e endividamento. Dessa forma, na Tabela 4 são apresentadas a média, a 
mediana, o desvio-padrão, o máximo e o mínimo dos seguintes indicadores: Retorno Sobre o Ativo (ROA), Retorno sobre o Patrimônio Líquido (ROE), Margem Líquida (ML), Lucro por Ação (LPA) e Endividamento (END).

No Painel A da Tabela 4, além desses indicadores, apresentam-se as estatísticas das concentrações de propriedade e de controle. Nesse Painel os dados são apresentados de forma crua, sem tratamento estatístico. Já no Painel B, apresentam-se com tratamento de Winsor para outlier, cujas variáveis foram winsorizadas a $1 \%$. Dessa forma, entre os anos de 2008 a 2012, percebe-se que, apesar disso, o valor médio do ROA após a exclusão dos outliers foi de $-13,69 \%$. Isso significa que, em média, os retornos sobre o ativo das empresas foram negativos.

Já o ROE apresentou valores positivos com média de 6,67\%. Levando em comparação a média obtida no estudo de Caixe e Krauter (2013), este resultado para o período de 2008 a 2012 é um pouco menor, pois o ROE médio dos autores supracitados foi equivalente a 15,19\%. Mas essa diferença se dá devido às diferenças de amostra e período investigado.

Assim como o ROA, a ML apresentou média negativa, igual a $-45,91 \%$, indicando que, em médias, as companhias analisadas neste estudo tiveram desempenho negativo em relação a sua receita líquida de vendas. Todavia, quando observado o lucro por ação (LPA), a média foi positiva, em cerca de 0,86\%. Por fim, o indicador de endividamento geral (END) entre 2008 e 2012, para as empresas analisadas, teve média de 151,07\%, indicando alto endividamento.

Tabela 4- Estatísticas descritivas das variáveis (\%). 2008 - 2012.

\begin{tabular}{|c|c|c|c|c|c|}
\hline PAINEL A - Dados Brutos & Média & $\begin{array}{l}\text { Median } \\
\quad \text { a }\end{array}$ & $\begin{array}{l}\text { Desvio } \\
\text { Padrão }\end{array}$ & Máximo & Mínimo \\
\hline Ações Totais - Maior & 43,05 & 37,69 & 19,67 & 100,00 & 3,54 \\
\hline Ações Totais - 3 Maiores & 61,98 & 61,60 & 18,46 & 100,00 & 3,60 \\
\hline Ações Totais - 5 Maiores & 67,31 & 68,43 & 16,88 & 100,00 & 3,60 \\
\hline Ações Ordinárias - Maior & 52,84 & 52,05 & 22,04 & 100,00 & 3,40 \\
\hline Ações Ordinárias - 3 Maiores & 71,67 & 74,25 & 19,33 & 100,00 & 4,37 \\
\hline Ações Ordinárias - 5 Maiores & 76,23 & 78,89 & 17,24 & 100,00 & 4,37 \\
\hline Retorno sobre o Ativo (ROA) & $-38,07$ & 0,03 & 75,47 & 3,30 & $-23735,57$ \\
\hline $\begin{array}{l}\text { Retorno sobre o Patrimônio } \\
\text { (ROE) }\end{array}$ & $-0,30$ & 9,54 & 31,68 & 876,29 & $-5451,53$ \\
\hline \multirow[t]{2}{*}{ Margem Líquida (ML) } & - & 5,98 & $5.936,68$ & $46.635,17$ & - \\
\hline & $\begin{array}{c}2.895,7 \\
2\end{array}$ & & & & $967.261,82$ \\
\hline Lucro por Ação (LPA) & 1,34 & 0,41 & 5,19 & 460,98 & $-315,07$ \\
\hline Endividamento (END) & $\begin{array}{c}1.588,6 \\
4\end{array}$ & 59,78 & $2.963,14$ & $\begin{array}{c}855.528,5 \\
7\end{array}$ & 0,04 \\
\hline PAINEL B - Dados Tratados* & Média & $\begin{array}{l}\text { Median } \\
\text { a }\end{array}$ & $\begin{array}{l}\text { Desvio } \\
\text { Padrão }\end{array}$ & Máximo & Mínimo \\
\hline Ações Totais - Maior & 43,07 & 37,69 & 19,65 & 100,00 & 7,85 \\
\hline Ações Totais - 3 Maiores & 62,03 & 61,60 & 18,42 & 100,00 & 16,69 \\
\hline Ações Totais - 5 Maiores & 67,37 & 68,43 & 16,81 & 100,00 & 19,01 \\
\hline Ações Ordinárias - Maior & 52,87 & 52,05 & 22,01 & 100,00 & 9,09 \\
\hline Ações Ordinárias - 3 Maiores & 71,72 & 74,25 & 19,27 & 100,00 & 17,50 \\
\hline Ações Ordinárias - 5 Maiores & 76,32 & 78,89 & 17,15 & 100,00 & 20,83 \\
\hline Retorno sobre o Ativo (ROA) & $-13,69$ & 3,14 & 33,60 & 45,91 & $-941,01$ \\
\hline $\begin{array}{l}\text { Retorno sobre o Patrimônio } \\
\text { (ROE) }\end{array}$ & 6,67 & 9,54 & 18,69 & 127,54 & $-235,51$ \\
\hline
\end{tabular}




\begin{tabular}{lccccc} 
Margem Líquida (ML) & $-45,91$ & 5,98 & 120,13 & 517,08 & $-3.464,54$ \\
Lucro por Ação (LPA) & 0,86 & 0,41 & 3,13 & 52,06 & $-42,78$ \\
Endividamento (END) & 151,07 & 59,78 & 171,48 & $4.910,07$ & 2,28 \\
\hline
\end{tabular}

Fonte: Dados da pesquisa. Nota: * Suavização de outliers pela técnica de Winsor a $1 \%$.

\subsection{RELAÇÃO COM O DESEMPENHO DAS EMPRESAS}

Além de analisar as estruturas de propriedade e de controle das empresas, foram estimadas regressões simples entre cada um dos cinco indicadores financeiros e cada grupo de acionistas (o maior, os três e os cinco maiores) detentores de propriedade e de controle.

Na Tabela 5, das regressões simples estimadas para a concentração de propriedade e de controle, é possível verificar que na primeira coluna constam os indicadores financeiros regredidos à propriedade (segunda coluna) e a controle (terceira coluna). Assim, são apresentados os coeficientes das regressões, com as estatísticas $t$ logo abaixo (entre parênteses) e a indicação dos níveis de significância de cada coeficiente.

Para a concentração de propriedade e também para a de controle, observa-se a forte relação entre o ROA e o grupo do maior acionista (-0,019 e $-0,018$, respectivamente), mostrando que a concentração dessas estruturas nas mãos do maior acionista influencia negativamente o desempenho da firma. Isso pode ser justificado devido ao fato de que, segundo Gonzaga e Costa (2009), os acionistas têm influência sobre os gestores da entidade. Assim, esses acionistas interferem nas decisões dos gestores e consequentemente no desempenho da empresa.

É possível perceber, também, que aumentando a quantidade de acionistas que concentram as ações para os 3 e os 5 maiores, a significância do ROA para com essas estruturas diminui, principalmente quando se trata da estrutura de propriedade, que envolve ações com e sem direito a votos. Quando se trata da estrutura de controle ainda se observa significância, devido a essa estrutura tratar apenas de concentração de votos, que podem influenciar os gestores, principalmente com relação aos 5 maiores controladores. Assim, percebe-se que quando o controle está diluído nas mãos de mais acionistas, a influência sobre o ROA tende a diminuir, o que pode ser verificado pela redução da negatividade dos coeficientes.

Nas regressões simples que envolvem o ROE, observa-se que há relação significante apenas com a estrutura de propriedade, sendo a mais forte com os grupos de maior e 3 maiores acionistas $(0,021$ e 0,020 , respectivamente), com coeficientes e estatísticas $t$ significantes ao nível de $5 \%$. Assim, é possível verificar um impacto positivo sobre esse indicador. Já quanto à concentração de controle, não houve significância.

A falta de significância entre o controle e o ROE é equivalente ao estudo de Dami, Rogers, Silva e Ribeiro (2007) onde, entre os anos de 1997 e 2001, não foi verificada relação do ROE com o grau de concentração do controle. Semelhante a esse resultado, foi o encontrado por Campos (2006), entre o ROE e a concentração do controle entre os anos de 1998 a 2001, em que não foi constatada relação entre essas variáveis e a explicação foi que, possivelmente, esses acionistas que possuem o controle da entidade têm suas ações voltadas para a rentabilidade de curto prazo e não para o retorno sobre o patrimônio líquido.

Tabela 5- Regressões simples para concentração de propriedade e controle. 2008 - 2012.

\begin{tabular}{l|ccc|ccc}
\hline \multirow{2}{*}{ Variáveis } & \multicolumn{3}{|c|}{ Propriedade } & \multicolumn{3}{c}{ Controle } \\
& Maior & 3 Maiores & 5 Maiores & Maior & 3 Maiores & 5 Maiores \\
\hline \multirow{2}{*}{ ROA } & $-0,019$ & $-0,007$ & $-0,007$ & $-0,018$ & $-0,009$ & $-0,010$ \\
& $(-4,681)^{* * *}$ & $(-1,715)^{*}$ & $(-1,547)$ & $(-$ & $(-2,061)^{* *}$ & $(2,173)^{* *}$ \\
\hline
\end{tabular}

Revista de Contabilidade e Controladoria, ISSN 1984-6266

Universidade Federal do Paraná, Curitiba, v. 7, n.2, p. 110 -126, mai./ago. 2015. 


\begin{tabular}{l|ccc|ccc}
\hline & \multicolumn{7}{|c|}{$3,947)^{* * *}$} \\
\hline \multirow{2}{*}{ ROE } & 0,021 & 0,020 & 0,012 & 0,014 & 0,015 & 0,008 \\
& $(2,351)^{* *}$ & $(2,214)^{* *}$ & $(1,301)$ & $(1,380)$ & $(1,473)$ & $(0,881)$ \\
\hline \multirow{2}{*}{ ML } & 0,001 & 0,002 & 0,002 & 0,001 & 0,001 & 0,001 \\
& $(0,778)$ & $(1,695)$ & $(1,825)$ & $(0,7436)$ & $(0,767)$ & $(0,837)$ \\
\hline \multirow{2}{*}{ LPA } & $-0,044$ & $-0,065$ & $-0,072$ & $-0,046$ & $-0,072$ & $-0,077$ \\
& $(-0,957)$ & $(-1,424)$ & $(-1,485)$ & $(-0,931)$ & $(-1,565)$ & $(-1,669)^{*}$ \\
\hline \multirow{2}{*}{ END } & 0,003 & 0,001 & 0,001 & 0,003 & 0,002 & 0,002 \\
& $(3,333)^{* * *}$ & $(1,642)$ & $(1,403)$ & $(3,074)^{* * *}$ & $(2,173)^{* *}$ & $(2,327)^{* *}$ \\
\hline
\end{tabular}

Nota:ROA é o retorno sobre o ativo, ROE é o retorno sobre o patrimônio líquido, ML é a margem líquida, LPA é o lucro por ação e END é o endividamento. Regressões simples rodadas independentemente, onde se apresenta o coeficiente do regressor e sua estatística $t$ (entre parênteses), onde ${ }^{* * *}$ é significante ao nível de $1 \%,{ }^{* *}$ de $5 \%$ e * de $10 \%$.

Como apresenta a Tabela 5, não foi possível identificar relação significante entre a ML e as estruturas de propriedade e controle, como também entre o LPA e essas estruturas. Por isso, não se pode afirmar que essas relações são diferentes de zero. Uma fraca relação ainda foi possível de ser observada entre a concentração de controle dos 5 maiores acionistas e o LPA, mas apenas ao nível de $10 \%$. Quanto ao endividamento geral (END), a relação foi positiva e significante com a concentração de propriedade do maior acionista $(0,003)$. Ou seja, quanto maior a concentração da estrutura de propriedade, maior o índice de endividamento, o que é razoável, pois a empresa tende a recorrer a capital terceiros.

Foi possível verificar uma significativa relação entre o END e a concentração de controle, especialmente para o maior acionista (significante a $1 \%$ ). Nos três casos a relação foi positiva e significante $(0,003,0,002$ e 0,002, respectivamente). Considerando que, no geral, a relação entre o END e a estrutura de controle foi mais significativa do que com a estrutura de propriedade, talvez os controladores prefiram recorrer ao capital de terceiros do que incentivar a emissão de novas ações, como forma de se manter no controle, ou por considerar o custo do capital de terceiros menos oneroso. Diferentemente do estudo realizado por Soares e Kloeckner (2008), o qual apontou que as empresas que possuem um acionista controlador tendem a evitar ou possuem dificuldades de se financiar com terceiros.

Assim, de forma geral, a Hipótese 3 , de que empresas que possuem maior concentração de propriedade e de controle possuem melhor desempenho financeiro pode ser rejeitada, pois, apesar de a relação da concentração de propriedade ter sido positiva com o ROE, foi negativa e significante com o ROA. Por isso não é possível atestar que maior concentração implica melhor desempenho financeiro.

\section{CONCLUSÃO}

O objetivo deste trabalho foi investigar as relações das estruturas de propriedade e controle com o desempenho das empresas não financeiras listadas na BM\&FBOVESPA entre os anos de 2008 e 2012. Fez parte da amostra 332 empresas não financeiras que possuíam suas ações negociadas nesse mercado. Destaca-se, ainda, o período de realização deste estudo, posterior à crise econômica de 2008 e às mudanças na estrutura das demonstrações contábeis, provenientes da Lei № 11.638/2007, como parte do processos de convergências das normas contábeis brasileiras ao padrão internacional (IFRS). 
Os resultados mostraram que as empresas no mercado brasileiro possuem alta concentração de propriedade e de controle durante o período analisado, pois ainda concentram, em média, quase metade de seu capital total e mais da metade do capital votante em um único investidor, confirmando a Hipótese 1 deste estudo. Porém, esse é um cenário que vem se modificando ao longo dos anos, haja vista a diminuição dessas concentrações, o que pode estar ocorrendo devido à entrada de novos investidores nesse mercado. Se mais acionistas estão fazendo parte do mercado, a tendência é que ocorra a diluição da concentração da propriedade e do controle durante os próximos anos.

Também foi possível observar que há maior concentração de capital votante (controle) do que de capital total (propriedade), confirmando a Hipótese 2 deste estudo, o que sugere que as empresas no Brasil buscam pulverizar seu capital por meio de ações preferenciais, sem direito de voto, uma das formas que os controladores encontraram de se manter no controle. Apesar dessa ser uma prática desestimulada pelos principais órgãos que fomentam o mercado de capitais no Brasil, como a própria BM\&FBOVESPA, a Comissão de Valores Mobiliários (CVM) e o Instituto Brasileiro de Governança Corporativa (IBGC), verifica-se que algumas empresas ainda resistem a essa mudança de postura.

Quanto às relações das estruturas de propriedade e de controle com os indicadores de desempenho, foi possível verificar relações significantes, apesar de algumas variáveis terem apresentado baixos coeficientes, indicando reflexos pequenos. O Retorno sobre o Patrimônio Líquido (ROE) e o Endividamento (END) apresentaram relação positiva com a concentração de propriedade e controle, enquanto o ROA relação negativa. Isso provavelmente se deve ao fato de os acionistas controladores possuírem influência sobre as decisões das empresas e, também, monitoramento dos gestores da entidade, principalmente quando a empresa é controlada por um só acionista.

Por fim, com base nessas evidências, a Hipótese 3 deste estudo não puder ser confirmada, pois se verificou que a rentabilidade do ativo apresentou relação negativa, enquanto a rentabilidade do patrimônio líquido relação positiva, assim como o endividamento geral. Todavia, alerta-se para as limitações deste estudo, que utilizou uma base de dados secundária, durante o período de 2008 a 2012, com uma amostra de empresas que representa apenas um recorte da realidade em questão. É relevante informar que os anos 2008 e 2009 foram o período de adaptação das normas brasileiras às IFRS, portanto as demonstrações de ambos os anos podem apresentar divergências em relação àquelas dos anos a partir de 2010, quando houve o chamado full IFRS, em que as empresas abertas foram obrigadas a adotas todas as normas convergidas. No entanto, tais limitações não invalidam o estudo.

\section{REFERÊNCIAS}

ALDRIGHI, D. M.; MAZZER NETO, R. Evidências sobre as estruturas de propriedade de capital e de voto das empresas de capital aberto no Brasil. Revista Brasileira de Economia, v. 61, n. 2, p. 129-152, 2007.

BASTOS, D. D.; NAKAMURA, W. T.; DAVID, M.; ROTTA, U. A. S. A relação entre o retorno das ações e as métricas de desempenho: evidências empíricas para as companhias abertas no Brasil. Revista de Gestão-USP, v. 16, n. 3, p. 65-79, 2009.

BERLE, A. A.; MEANS, G. C. The modern corporation and private property. New York: MacMillan, 1932.

BIRAL, R. A. F. A abertura de capital afeta o desempenho operacional das empresas? Evidência da onda de IPOs 2004-2008. (Dissertação) Escola de Economia de São Paulo, São Paulo/SP, 2010. 
BORSATO, J. M. L. S.; PIMENTA, D. P.; Lemes, S. A influência da controladoria no processo de abertura de capital: um estudo de caso em uma instituição de ensino superior. Revista de Contabilidade do Mestrado em Ciências Contábeis da UERJ, v. 15, n. 3, p. 51-64, 2010.

CAIXE, D. F.; KRAUTER, E. A influencia da estrutura de propriedade e controle sobre o valor de mercado corporativo no Brasil. Revista Contabilidade \& Finanças, v. 24, n. 62, p. 142-153, 2013.

CAMPOS, T. L. C. Estrutura da propriedade e desempenho econômico: uma avaliação empírica para as empresas de capital aberto no Brasil. Revista de Administração da USP, v. 41, n. 4, p. 369-380, 2006.

CAMPOS, G. M.; SCHERER, L. M. Lucro por ação. Revista Contabilidade \& Finanças, v. 12, n. 26, p. 8194, 2001.

CAPOBIANGO, R. P.; ABRANTES, L. A.; FERREIRA, M. A. M.; FARONI, W. Desempenho financeiro: um estudo com empresas de três diferentes setores. Revista de Ciências Humanas, v. 12, n. 1, p. 165180, 2012.

CANEIRO, J.; SILVA, J. F. Medidas contábeis-financeiras como indicadores de desempenho organizacional: análise crítica de sua conceituação e operacionalização. eGESTA - Revista Eletrônica de Gestão de Negócios, v. 6, n. 3, p. 31-68, 2010.

COUTINHO, E. S.; AMARAL, H. F.; BERTUCCI, L. A. O impacto da estrutura de propriedade no valor de mercado de empresas brasileiras. Revista de Administração da USP, v. 41, n. 2, p. 197-207, 2006.

CPC - COMITÊ DE PRONUNCIAMENTOS CONTÁBEIS. Pronunciamentos Técnicos Contábeis. Conselho Federal de Contabilidade, Brasília/DF, 2010.

DAMI, A. B. T.; ROGERS, P.; RIBEIRO, K. C. S. Estrutura de propriedade no Brasil: evidências empíricas no grau de concentração acionária. Contextus - Revista Contemporânea de Economia e Gestão, v. 5, n. 2, p. 21-30 2007.

DELCI, G. D. V.; BEUREN, I. M. Teoria da estrutura de propriedade: redes sociais em periódicos internacionais de alto impacto. Revista Facultad de Ciencias Económicas: Investigación y Reflexión, v. 20, n. 1, p. 123-141, 2012.

DEMSETZ, H.; LEHN, K. The structure of corporate ownership: causes and consequences. Journal of Political Economy, v. 93, n. 6, p. 155-177, 1985.

DUARTE, J.; YOUNG L. Why is PIN priced? Journal of Financial Economics, v. 91, n. 2, p. 119-138, 2009.

GONZAGA, R. P.; COSTA, F. M. A relação entre o conservadorismo contábil e os conflitos entre acionistas controladores e minoritários sobre as políticas de dividendos nas empresas brasileiras listadas na Bovespa. Revista Contabilidade \& Finanças, v. 20, n. 50, p. 95-105, 2009.

GORGA, E. Changing the paradigm of stock ownership from concentrated towards dispersed ownership? Evidence from Brazil and consequences for emerging countries. Cornell Law Faculty Publications, Paper n.42, 2008. Disponível em: http://scholarship.law.cornell.edu/clsops papers/42/. Acesso em: 14 jan. 2014.

HAHN, A. V.; NOSSA, S. N.; TEIXEIRA, A. J. C.; NOSSA, V. Um estudo sobre a relação entre a concentração acionária e o nível payout das empresas brasileiras negociadas na Bovespa. Revista Contabilidade Vista \& Revista, v. 21, n. 3, p. 15-48, 2010. 
Hermalin, B. E., \& Weisbach, M. S. (1991). The effect of board composition and direct incentives on firm performance. Financial Management, 21(4), 101-112.

Ivo, M. P. C. (2012). Responsabilidade social, ambiental e desempenho financeiro nas empresas brasileiras de capital aberto. Dissertação de mestrado, Universidade Presbiteriana Mackenzie, São Paulo, SP, Brasil.

Kühl, M. R., Cherobim, A. P. M. S., \& Santos, A. R. (2008). Contabilidade Gerencial e mercado de capitais: o preço das ações em mercado é melhor explicado por indicadores internos da empresa ou por indicadores externos?. Revista Capital Científico, 6(1), 145-164.

La Porta, R., Shleifer, A., Lopes-De-Sinales, F., \& Vishny, R. (1998). Law and finance. Journal of Political Economy, 106, 1113-1155.

Leal, R. P. C., Silva, A. L. C., \& Valadares, S. M. (2002). Estrutura de controle das companhias brasileiras de capital aberto. Revista de Administração Contemporânea, 6(1), 7-18.

MARTINS, O. S.; PAULO, E. Assimetria de informação na negociação de ações, características econômico-financeiras e governança corporativa no mercado acionário brasileiro. Revista Contabilidade \& Finanças, 25, n. 64, p. 33-45, jan./fev./mar./abr. 2014.

McConnel, J. J., \& Servaes, H. (1990). Additional evidence on equity ownership and corporate value. Journal of Financial Economics, 27, 595-612.

Okimura, R. T. (2003). Estrutura de propriedade, governança corporativa, valor e desempenho das empresas no Brasil. Dissertação de mestrado, Universidade de São Paulo, SP, Brasil.

Okimura, R. T., Silveira, A. M., \& Rocha, K. C. (2007). Estrutura de propriedade e desempenho corporativo no Brasil. RAC-Eletrônica, 1(1), 119-135.

Peterson, P. P., \& Peterson, D. R. (1996). Performance de empresas e medidas de valoradicionado. Fundação de Pesquisa do Instituto de Analistas Financeiros Certificados, Virginia.

Santos, M. R., Coda, R., \& Mazzali, L. (2010). Clima organizacional e desempenho financeiro. Revista Universo Contábil, 6(2), 27-46.

Sarlo Neto, A., Lopes, A. B., \& Dalmácio, F. Z. (2010). A influência da estrutura de propriedade sobre a informatividade dos lucros contábeis divulgados pelas empresas negociadas na BOVESPA. BASERevista de Administração e Contabilidade da Unisinos, 7(4), 301-314.

Sarlo Neto, A., Loss, L., Teixeira, A. J. C., \& Lopes, A. B. (2005). O diferencial no impacto dos resultados contábeis nas ações ordinárias e preferenciais no mercado brasileiro. Revista Contabilidade \& Finanças, 16(37), 46-58.

Silveira, A. M., Barros, L. A. B. C., \& Famá, R. (2008). Atributos corporativos e concentração acionária no Brasil. Revista de Administação de Empresas - RAE, 18(2), 51-66.

Soares, R. O., \& Kloeckner, G. O. (2008). Endividamento em firmas com alta propensão à expropriação: o caso de firmas com um controlador. Revista de Administração de Empresas - RAE, 48(4), 79-93.

Vieira, S. P., \& Mendes, A. G. S. T. (2006). Governança corporativa: uma análise de sua evolução e impactos no mercado de capitais brasileiro. Organizações em Contexto, 2(4), 48-67. 